\title{
Dengue fever follows plague as India's woes mount
}

Poor environmental and sanitary

standards have been blamed for

the dengue hemorrhagic fever

(DHF) epidemic that swept the capital city of New Delhi in September and October. Caused by a virus transmitted by female Aedes aegrpti mosquitoes, DHF killed 300 people and hospitalized 8000 more, causing panic in a city that hasn't recovered from the shock of last year's plague outbreak (Nature Medicine 1, 724; 1995).

"What we witnessed recently was the emergence of hemorrhagic form of dengue, and this is cause for con- cern," says Vulimiri Ramalingaswami, former chief of the Indian Council of Medical Research. Moving westward from southeast Asia, where DHF is endemic, this form of dengue "has now secured a firm foothold in India."

A clean-water breeder, the daybiting Aedes mosquitoes were found to be emerging from thousands of domestic coolers and overhead water tanks - both signs of urbanization - and numerous tire dumps, a fallout of the automobile revolution. The World Health Organization (WHO) regional office in New Delhi declared that the Delhi outbreak and the ris- ing incidence of DHF in the southeast Asian region as a whole is a result of falling environmental standards due to urbanization.

Following last year's plague outbreak, the National Institute of Communicable Diseases (NICD) in New Delhi had proposed a disease surveillance and early warning system covering 100 of India's 540 districts (Nature Medicine 1, $861 ; 1995)$, specifically to catch things like DHF before they had spread too far. But the system never materialized, because the World Bank rejected India's request for a US\$60 million loan to establish it. NICD director Krishna Kumar Dutta says that the emergence of DHF "is a signal that we should not delay establishing the system any longer."

K.S. JAYARAMAN New Delhi, India

\section{An outline of the human genome}

A table of contents for the human genome has long been the dream of disease-gene hunters. Now a team of scientists one hundred strong has published a unified human gene map that details the sequence and location of 16,334 known genes (one-fifth of the calculated 80,000 genes strung out along the 23 pairs

\section{Peer-review court battle averted}

In a move that surprised most observers, Immunex Corporation of Seattle, Washington, agreed last month to settle its case with Cistron Biotechnology of Piney Brook, New Jersey, out of court. Immunex will pay US $\$ 21$ million as well as cede certain of the patents in question [for human interleukin-1 (IL-1)] to Cistron, without having to admit guilt.

Although the patent rights to IL-1 were arguably the prize at stake in this battle, the case is distinguished from similar biotechnology patent fights because it threatened to drag the unwritten code of ethics that underpins the peer-review process before a court of law. Cistron accused Immunex of stealing data from a paper, submitted originally to Nature, that an Immunex scientist had received for peer review. Furthermore, Cistron claimed that Immunex used the information to further its own research and to bol- ster its own patent claim. As it turns out, the paper in question was ultimately rejected by Nature, although the Immunex group subsequently published its own IL-1 paper in Nature.

Immunex was prepared to argue before the court that it had done the work independently, despite the fact that certain DNA sequence errors appeared in both the original Cistron paper and in Immunex's patent application. But, of intense interest to scientists SCIENCE96/.

\section{Surgical instrument turns up unexpectedly}

Mourners at a cremation in Kumamoto, southern Japan, were shocked to see 14-cm-long surgical scissors among the ashes of a 65-year-old man, who had recently undergone surgery for lung cancer at Kumamoto Citizens General hospital in September. During surgery he suffered a heart attack and died three weeks later. X-rays taken after the operation did not reveal any scissors left inside the man, which has lead hospital doctors to conclude that the scissors were mislaid during a subsequent autopsy. The head of the hospital personally visited the relatives of the deceased to apologize and has called on doctors at the hospital to take better care of their equipment.

RICHARD NATHAN Tokyo, Japan of human chromosomes). The new map is an impressive example of international cooperation; it involves genome laboratories in the United States, Canada, Europe and Japan, and has received private and public sector sponsorship from three different continents. The map will

likely speed up the identification of genes underlying inherited human diseases and already has revealed important information about how the genome is organized. The gene map is available to both scientists and the public on the National Library of Medicine's World Wide Web site - http://www.ncbi.nlm.nih.gov/

ORLA SMITH

and scientific publishers, Immunex was also set to argue that there is no legally binding prohibition against using data from manuscripts one has received for peer review, and that once a manuscript is submitted for review it is no longer considered secret.

Both sides had prepared a formidable list of witnesses to argue their beliefs about peer review. Unfortunately - or perhaps fortunately - neither side will get their chance in this case. Nevertheless, serious questions have been raised again about the privacy of the peer-review process, questions that will undoubtedly get their day in court.

FINTAN R. STEELE 